(a) under the assumption that all the calcium with mass 41 was extracted, $1 \cdot 6 \times 10^{11}$ years.

(b) under the assumption that only one third was extracted, $0.5 \times 10^{11}$ years.

The Rhiconich and Portsoy rocks give identical figures, and the value indicated is of the order $1 \times 10^{11}$ years, which is in accordance with the revised results of Holmes and Lawson, not with the more recent work of Mühlhoff ${ }^{3}$.

JAMES Kendati.

William W. SMith.

Thomas TaIT.

Chemistry Department,

University, Edinburgh. April 4.

NAtroke, 131, 688, May 13, 1933.

Geological Survey, Summary of Progress for 1919, pp. 43-4.

Ann. Rep. Chem. Soc., 27, 310-11; 1930.

\section{The Helmholtz Resonance Theory of Hearing}

Direcr evidence in favour of the view that the vibrating elements of the cochlea are differentially tuned for frequency has been adduced in the following way :

The cochlea of the cat is exposed under Nembutal anæsthesia. Viewing the preparation through a dissecting microscope, and using a dental burr, small excavations are now made in the bone, one proximal to the round window, the other towards the apex of the cochlea; the floor of these concavities may be made so thin that the cochlear fluids seep through, a state of affairs which may be easily seen through the microscope. At this juncture, small beads of mercury are placed in the depressions, using a micro-pipette; in this way, further loss of fluid is prevented, and a good electrical contact with the fluids of the inner ear established, by the insertion of platinum electrodes into the mercury droplets.

In response to sound stimuli, potentials are engendered between these electrodes and an indifferent electrode placed beneath the mylo-hyoid muscle (Wever and Bray effect), and these may be recorded by means of an amplifier and oscillograph.

The amplitude of the potentials in response to a note of 250 cycles has been found to be three or more times as great at the apex as at the base; while a note of 2,050 cycles gives rise to potentials of amplitude some four times greater at the base than at the apex.

C. S. Hatupike.

A. F. Rawdon Smith.

Ferens Institute of Otology,

Middlesex Hospital Annexe, Cleveland Street, W.1. March 27.

\section{The Attitude of the German Government towards Science}

IN spite of my letter in NATURE of February 24, there still seems to exist in English scientific circles a misunderstanding of the attitude of the new Government in Germany towards science and of the reasons why Jewish scientists have left the country. May I be allowed therefore to point out the following facts?

It must be emphasised once more that it is far from the thought of the National Socialist Government to make an attack on the freedom of scientific investigation; rather is it anxious to give scientific persons every possible help for their work. I have myself on many occasions been asked by the National Socialist Ministers to join them in assisting individual scientific persons and institutes.

The National Socialist Government has not subjected Jewish scientists to exceptional treatment, or forced them to emigrate: it has passed a law for the reform of the Civil Service which applies to all kinds of officials, not only to those concerned with science. According to this law, non-Aryan officials were obliged to leave their positions if they were not appointed before 1914, or if they had not fought at the front in the War, or had not lost fathers or sons in the War. No Government can be denied the right to make such rules in the interests of its own people, and no group of officials, for example, scientific ones, can be made an exception to such a general law. As a matter of fact, however, in a number of individual cases an exception was made to the advantage of Jewish scientists.

Various Jewish scientists, without being forced to do so, have given up their professorships and moved to other countries. This they have done, as some of them have declared openly, out of sympathy with their Jewish kinsfolk who were affected by the law. This attitude can be understood and appreciated. One should not, however, set them up outside Germany as martyrs of unjust treatment by National Socialist Germany, nor quote them as signs of the denial of intellectual freedom in Germany. This would be a misunderstanding of the actual position.

The withholding of criticism of the new regime in Germany, or at least a conscientious regard for the truth in scientific circles, will be to the advantage not only of international co-operation but also of the Jewish scientists themselves.

With regard to the assertions and opinions of my respected colleague, Prof. A. V. Hill, on the abovementioned matter, I should like to invite him to visit Germany and as a scientific investigator to get acquainted with the actual facts by means of his own observation and collection of evidence.

\section{J. STARK}

(President).

Physikalisch-Technische Reichanstalt, Berlin.

\section{Ancient Houses of North Rona}

IN a short notice of a book on Ronay ${ }^{1}$, the reviewer refers to the curious remains of dwelling houses on North Rona and likens them (from the description) to the dolmen of Locmariaquer and Carnac. In the latter part of October 1928, in the course of making a census of the grey seals of Scotland during the breeding season, on behalf of the Scottish Office, W. L. Calderwood and I landed on this island, seldom visited by naturalists or archæologists. The salient characteristics of the houses, which seem to have been inhabited in recent historic times, are that they are half-sunk in the ground, have a low wall of dry-stone construction rising above the surface, which probably carried a wooden roof made watertight by turves, and were entered not directly, but through a low and generally curved, roofed passage, along which the entrant had to crawl.

So far as I know, no suggestion has been made, other than the reviewer's, as to the origin of such a construction, and I write to direct attention to the 